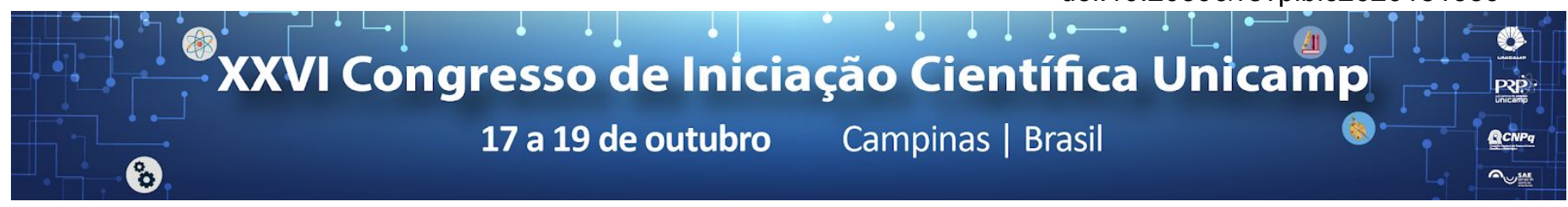

\title{
DESENVOLVIMENTO DE UM SISTEMA DE CONTROLE INTELIGENTE EM UM PROTÓTIPO EXPERIMENTAL DE FLOTAÇÃO POR AR DISSOLVIDO PARA TRATAMENTO DE ÁGUA.
}

\section{Vinícius Rozante*, Flávio V. da Silva.}

\section{Resumo}

A maioria dos processos químicos são inerentemente multivariáveis exibindo fortes interações entre as variáveis de processos, muitas vezes, sujeitas a restrições. Com o avanço da tecnologia, os sistemas e processos químicos ficaram mais complexos, tornando-se uma tarefa árdua, muitas vezes impossível, a utilização satisfatória dos controladores convencionais obtidos a partir da teoria clássica. Esta realidade desencadeou uma procura por novas estratégias de controle tais como: controle multivariável, controle adaptativo, controle preditivo e sistema de controle inteligente. Analisando este panorama, foi proposto, como foco principal deste projeto, o desenvolvimento de um sistema e automação aplicado a um protótipo experimental de flotação por ar dissolvido (FAD) que permitiu a implementação de uma estratégia de controle inteligente baseado em lógica fuzzy.

\section{Palavras-chave:}

Flotação, Controle fuzzy, Automação.

\section{Introdução}

Essencial à vida em todas as suas formas conhecidas na natureza, a água é uma substância em abundância no ecossistema terrestre.

O uso de técnicas eficientes no tratamento de água é de extrema importância, já que a água a ser tratada pode apresentar diferentes variedades e concentrações de poluentes. A flotação, principalmente por ar dissolvido (FAD), é um dos processos tipicamente empregados no tratamento de água na etapa de clarificação.

Este trabalho deu continuidade em uma nova linha de pesquisa no Laboratório de Controle e Automação de Processos (LCAP) com a automação de uma planta de flotação por ar dissolvido, assim como o desenvolvimento de sistemas de controle aplicados a este processo com o emprego da técnica de inteligência artificial na malha de controle.

\section{Resultados e Discussão}

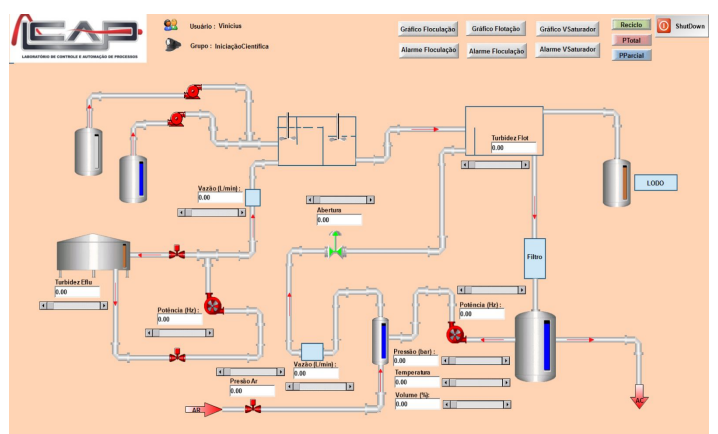

Figura 1. Tela de navegação principal do sistema SCADA da planta de FAD

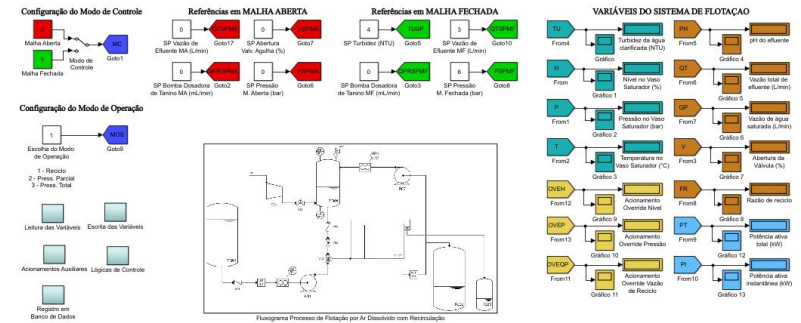

Figura 2. Malha de controle da planta FAD.

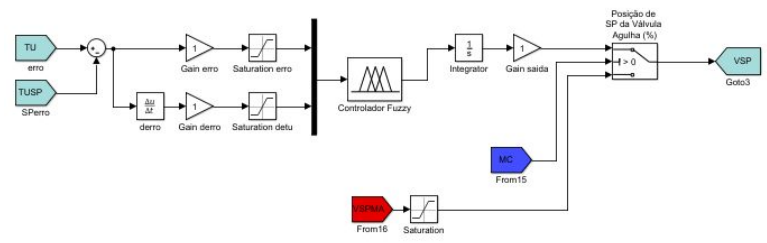

Figura 3. Malha de controle da turbidez de saída utilizando controlador fuzzy.

\section{Conclusões}

O sistema de controle desenvolvido foi eficiente na manutenção das condições de projeto da planta, em escala laboratorial, de flotação por ar dissolvido (FAD). A construção de um sistema supervisório facilitou 0 monitoramento on line de todas as variáveis de processo.

\section{Agradecimentos}

Agradecimento especial ao órgão SAE/UNICAMP pelo financiamento à pesquisa realizada.

ANG, Kiam Heong; CHONG, Gregory; LI, Yun. PID control system analysis, design, and technology. IEEE transactions on control systems technology, v. 13, n. 4, p. 559-576, 2005. 